\title{
Investigation on the Surface Hydrophobicity and Aggregation Kinetics of Human Calprotectin in the Presence of Calcium
}

\author{
Reza Yousefi, Susan K. Ardestani*, Ali Akbar Saboury, Amina Kariminia ${ }^{\dagger}$ Madjid Zeinali and Mojtaba Amani \\ Institute of Biochemistry and Biophysics, University of Tehran, Tehran, Iran \\ IImmunology lab., Pasteur Institute of Iran, Tehran, Iran
}

Received 22 December 2004, Accepted 2 March 2005

\begin{abstract}
Calcium and zinc binding protein, calprotectin is a multifunctional protein with broad spectrum antimicrobial and antitumoural activity. It was purified from human neutrophil, using a two-step ion exchange chromatography. Since surface hydrophobicity of calprotectin may be important in membrane anchoring, membrane penetration, subunits oligomerization and some biological roles of protein, in this study attempted to explore the effect of calcium in physiological range on the calprotectin lipophilicity. Incubation of human calprotectin $(50 \mu \mathrm{g} / \mathrm{ml})$ with different calcium concentrations showed that 1anilino-8-naphthalene sulfonic acid (ANS) fluorescence intensity of the protein significantly elevates with calcium in a dose dependent manner, suggesting an increase in calprotectin surface hydrophobicity upon calcium binding. Our study also indicates that calcium at higher concentrations $(6,8$ and $10 \mathrm{mM})$ induces aggregation of human calprotectin. Our finding demonstrates that the starting time and the rate constant of calprotectin aggregation depend on the calcium concentration.
\end{abstract}

Keywords: Aggregation, ANS-binding fluorescence, Calcium, Calprotectin, Hydrophobicity, Neutrophil

\section{Introduction}

Myeloid-related protein (MRP) 8 and MRP14 are two small anionic proteins, with zinc and calcium binding capacity; they belong to S-100 protein family and abundantly found in cytosolic fraction of neutrophils (Hessian et al., 1993; Bella and Rossmann, 1999). They form a heterodimeric complex in a calcium dependent manner that called MRP8/14,

\footnotetext{
* To whom correspondence should be addressed.

Tel: 9821-6409517; Fax: 9821-6404680

E-mail: ardestani@ibb.ut.ac.ir
}

calprotectin or cystic fibrosis antigen (Steinbakk et al., 1990; Murao et al., 1998). Human MRP8 and MRP14 have molecular masses of 11 and $14 \mathrm{kDa}$ with 93 and 114 amino acids, respectively. Each subunit of the protein is composed of two distinct calcium binding motifs (EF-hand) flanked by hydrophobic regions at either terminus and separated by a central hinge region (Ordink et al., 1987; Hessian et al., 1993).

Calprotectin shares properties with calmodulin but differ in molecular mass and it would be expected to exert a major biological effect by modifying the intracellular calcium level (Burgess et al., 1980). High concentration of calprotectin in neutrophil acts as calcium sink and may be protecting cells from harmful effect of prolonged calcium elevation.

Calcium is a key secondary messenger during signal transduction and calprotectin may binds to free intracellular calcium and interfere with signal transduction (Heizmann and Hunziker, 1991).

Calprotectin is a multifunctional protein with broad spectrum antimicrobial and antitumoural effects (Steinbakk et al., 1990; Satoru et al., 1997) that is significantly elevated in the serum and body fluids of patients with cystic fibrosis (Dorin et al., 1987) and inflammatory states such as rheumatoid arthritis (Berntzen et al., 1991), Crohn's disease (Lawrance et al., 2001) colorectal carcinoma (Tibble et al., 2001), multiple sclerosis (Bogumil et al., 1998) and human immunodeficiency virus (HIV) infection (Müller et al., 1994). Also the large subunit of calprotectin is expressed in brain tissue of those suffering from the amyloid disease, Alzheimer (Akiyama et al., 1994).

A variety of possible functions have been proposed for calprotectin such as the capacity for binding to poly unsaturated fatty acids (PUFAs) governed through calcium binding (Klempt et al., 1997; Kerkhoff et al., 1999). Investigators have shown that calprotectin inhibits the activity of casein kinases I and II (Murao et al., 1989), two enzymes that mediate RNA polymerase (Stetler et al., 1982; Rose et al., 1983) and topoisomerase activity (Ackerman et al., 1985).

Research also reveals that calcium binding induces 
conformational changes in the molecule, complex formation, phosphorylation of MRP14 and translocation (Edgeworth et al., 1989; Teigelkamp et al., 1991; Roth et al., 1993). Upon calcium binding, calprotectin translocates from the cytosol to the cytoskeleton and to the plasma membrane. As the protein kinase $\mathrm{C}$ (PKC) activates, this protein is released from human monocytes by a novel secretory pathway that is energy consuming and depends on the intact microtubule network (Roth et al., 1993; Guignard et al., 1996; Rammes et al., 1997). Since the protein does not contain a membrane anchoring region or signal peptide for secretion, the mechanism by which calprotectin penetrates the plasma membrane and how this protein complex is anchored in the membrane is unclear (Muesch et al., 1990). Hence surface hydrophobicity of calprotectin may be important in membrane anchoring, membrane penetration, subunits oligomerization and probably some biological roles of this protein.

In this study, we attempted to examine the effect of calcium concentration at physiological range on the human calprotectin lipophilicity. Also we investigated calprotectin aggregation at higher calcium concentrations. Aggregation can be associated with aberrant interaction with metal ions, changes in environmental conditions such as $\mathrm{pH}$ or temperature or chemical modification (oxidation and proteolysis), specific mutation and miss processing phenomena (Stefani and Dobson, 2003). Early aggregates have an intrinsic ability to impair fundamental cellular processes by interacting with cellular components (Bucciantini et al., 2002). The presence of toxic aggregates inside or outside of cells can impair a number of cell functions that ultimately lead to cell death (Morishima et al., 2001). The mechanism for calprotectin cell-death inducing activity is not precisely clear and calciuminduced calprotectin aggregation may be important in the celldeath inducing pathway of this protein.

\section{Materials and Methods}

Materials Dithiothreitol (DTT) and Lymphoprep were obtained from the Merck and Amersham Company, respectively. Fetal calf serum (FCS) was obtained from veterinary faculty at the University of Tehran. RPMI 1640 medium, Penicillin, Streptomycin and all other reagents and solvents were purchased from Sigma Chemical Co. (St. Louis, USA) and were at least of analytical grade. All solutions were made in double -distilled water.

Cell line K562 Chronic myelogenous leukemia cells were obtained from the cell bank of Pasteur Institute of Iran. These cells were maintained in RPMI 1640 medium supplemented with 10\% FCS in a humidified incubator $\left(37^{\circ} \mathrm{C}\right.$ and $\left.5 \% \mathrm{CO}_{2}\right)$.

Neutrophil isolation and extraction Fresh human blood was collected randomly from healthy donors into heparinated plastic bags and leukocytes isolation was performed by the dextran sedimentation in principle according to Skoog and Beck (Skoog, and Beck, 1956). One unit of $500 \mathrm{ml}$ heparinated blood was mixed with $250 \mathrm{ml}$ dextran T-500 (solution 6\%). Sedimentation was allowed to proceed for $45 \mathrm{~min}$ at room temperature. The supernatant layer was harvested and leukocytes were spun down at $200 \times \mathrm{g}$ for $20 \mathrm{~min}$ at $4^{\circ} \mathrm{C}$. Remaining red cells were lysed by the addition of ice-cold distilled water to the sediment and isotonicity was restored after $30 \mathrm{~s}$ by addition of phosphate-buffered saline (PBS). After being washed twice in PBS, granulocytes were separated from mononuclear cells by layering $3 \mathrm{ml}$ suspensions on the top of $6 \mathrm{ml}$ lymphoprep followed by centrifugation at $800 \times \mathrm{g}$ for $30 \mathrm{~min}$ at $20^{\circ} \mathrm{C}$.

Granulocytes (neutrophils) were resuspended in PBS containing $0.2 \mathrm{M}$ sucrose, $1 \mathrm{mM}$ EDTA, $1 \mathrm{mM}$ DTT and $0.5 \mathrm{mM}$ phenyl methyl sulfonyl fluoride (PMSF). The cell suspension was sonicated for $30 \mathrm{~s}$, five times by probe type sonicator (Model MK23.75, MSE, France). During this procedure, the cell container was kept in wet ice. After sonication the soluble fraction was separated from cell debris by centrifugation at $12000 \times g$ for $10 \mathrm{~min}$ at $4^{\circ} \mathrm{C}$ and clear supernatant (crude neutrophil extract) was collected.

Purification of calprotectin Crude neutrophil extract was dialyzed against $25 \mathrm{mM}$ Tris- $\mathrm{HCl}, \mathrm{pH}$ 8.0, $1 \mathrm{mM}$ EDTA, $1 \mathrm{mM}$ DTT (Buffer I) and injected onto anion exchange column (QSepharose) that has been pre-equilibrated with five column volumes of buffer I at a flow rate of $1 \mathrm{ml} / \mathrm{min}$. Bound proteins were eluted from the column by the application of $0-0.5 \mathrm{M} \mathrm{NaCl}$ gradient in buffer I over $150 \mathrm{~min}$, at $4^{\circ} \mathrm{C}$. Anion exchange eluted fractions were analyzed by Tricine-SDS-PAGE (Gel 15\%) under reducing conditions. To check growth inhibition of calprotectin-containing fractions, K562 cells were used as target.

These fractions were further dialyzed against $25 \mathrm{mM}$ sodium acetate $\mathrm{pH}$ 4.5, $1 \mathrm{mM}$ EDTA, $1 \mathrm{mM}$ DTT (buffer II) and injected onto cation exchange column (SP-Sepharose) that pre-equilibrated with five column volumes of buffer II at flow rate of $1 \mathrm{ml} / \mathrm{min}$. Bound proteins were eluted from the column by the application of $0-1.0 \mathrm{M} \mathrm{NaCl}$ gradient in buffer II over $100 \mathrm{~min}$. At this stage MRP8 and MRP14 appeared to be essentially pure ( $>98 \%)$ with densitometric analysis of SDS-PAGE gel that visualized by Coomassie Blue staining.

Dialysis was performed in 1000 molecular weight cut-off dialysis tubing at all stages. The purified protein was aliquoted and stored at $-70^{\circ} \mathrm{C}$ for the long term and at $4^{\circ} \mathrm{C}$ for short term use.

Electrophoresis For Tricine-SDS-PAGE, the method described by Schägger and von Jagow was used (Schägger and von Jagow, 1987). Samples were boiled in sample buffer with mercaptoetanol for $5 \mathrm{~min}$ and electrophoresed on poly-acrylamide gel (separating: $16.5 \%$ T, 3\% C; Stacking: 4\% T, 3\% C) at 200V. Protein bands were visualized by Coomassie brilliant blue staining.

Protein assay The protein concentration was determined by using the Bradford reagent (Bio-Rad, Richmond, USA) with bovine serum albumin (BSA) as standard (Crestfield et al., 1963).

Cell culture K562 cells were grown in RPMI with $10 \%$ heatinactivated fetal calf serum (FCS), supplemented with $4 \mathrm{mM} \mathrm{L}$ glutamine, $100 \mathrm{U}$ penicillin, $100 \mu \mathrm{g} / \mathrm{ml}$ streptomycin at $\mathrm{pH} 7.4$, in a humidified, $5 \% \mathrm{CO}_{2}$ incubator and temperature of $37^{\circ} \mathrm{C}$. Harvested cells were seeded into 96-well plates $\left(2 \times 10^{4} \mathrm{cell} / \mathrm{ml}\right)$ and 
proliferation curves for K562 were determined based on MTT assay.

Cell proliferation assay Relative cell number was measured using 3-(4, 5-dimethylthiazol-2-yl)-2, 5-diphenyl tetrazolium bromide (MTT) assay as described by Mossman (Mossman, 1983).

MTT (Sigma catalog no M2128) was dissolved in PBS at a concentration of $5 \mathrm{mg} / \mathrm{ml}$ and solution was filtered through a 0.5 $\mu \mathrm{m}$ filter, then it stored at $2-8^{\circ} \mathrm{C}$ for frequent use. Four hours before the end of incubations, $25 \mu \mathrm{l}$ of MTT solution ( $5 \mathrm{mg} / \mathrm{ml}$ in PBS) was added to each well containing fresh and cultured medium. The insoluble formazan produced was dissolved in a solution containing $10 \%$ SDS and $50 \%$ DMF (left for $2 \mathrm{~h}$ at $37^{\circ} \mathrm{C}$ in dark conditions) and the optical density (OD) was read against a reagent blank with multi well scanning spectrophotometer (ELISA reader, Model Multiskan MS) at a wavelength of $540 \mathrm{~nm}$ (OD540). The OD value of study groups was divided by the OD value of untreated groups and results presented as percentage of control groups (as 100\%).

Turbidity measurements The turbidity of human calprotectin $(50 \mu \mathrm{g} / \mathrm{ml})$ in $0.1 \mathrm{M}$ ammonium acetate, at $\mathrm{pH} 7.0$ and $25^{\circ} \mathrm{C}$ was monitored by measuring the light absorption at $420 \mathrm{~nm}$, using a Cary spectrophotometer (Model Bio-100). The obtained data were fitted to equation (1), (Kurganov, 2002).

$$
\mathrm{A}=\mathrm{A}_{\lim }\left(1-\mathrm{e}^{-\mathrm{k}\left(\mathrm{t} \mathrm{t}_{\mathrm{o}}\right)}\right)
$$

Where $A_{\lim }$ is the limiting value of absorbance (A) at $t \rightarrow \infty, k$ represents the first-order rate constant for aggregation reaction, $t$ indicates time and $\mathrm{t}_{\mathrm{o}}$ represents aggregation starting time.

ANS-binding experiments 1-anilino-8-naphthalene sulfonic acid (ANS) was added to calprotectin solution. After incubation for 15 $\mathrm{min}$, the fluorescence spectra were recorded at room temperature between 450 and $600 \mathrm{~nm}$, using an excitation wavelength of 400 $\mathrm{nm}$. All necessary back ground correction was made. The fluorescence measurements were made on Hitachi Spectrofluorimeter (Model MPF-4).

Statistical analysis Results were analyzed for statistical significance using two-tailed student's t-test. Changes were considered significant at $p<0.05$.

\section{Results and Discussion}

Purification of human calprotectin Human calprotectin (MRP8/14) was purified from neutrophil cytosol, using a protocol devised for the rapid purification of large quantities of protein. Neutrophil cytosol containing a maximum of 35 $\mathrm{mg}$ of total protein was injected onto a Q-sepharose anion exchange column. MRP8 and MRP14 were eluted from the column at approximately $0.12 \mathrm{M}, \mathrm{NaCl}$. Figures $1 \mathrm{a}$ and $1 \mathrm{~b}$ show chromatogram and SDS-page profile of anion exchange column, respectively. By densitometric scannining of a coomassie blue-stained sample after SDS-PAGE, following Q-sepharose chromatography, the majority of MRP8 and MRP14 were observed to elute in a single peak (fractions a

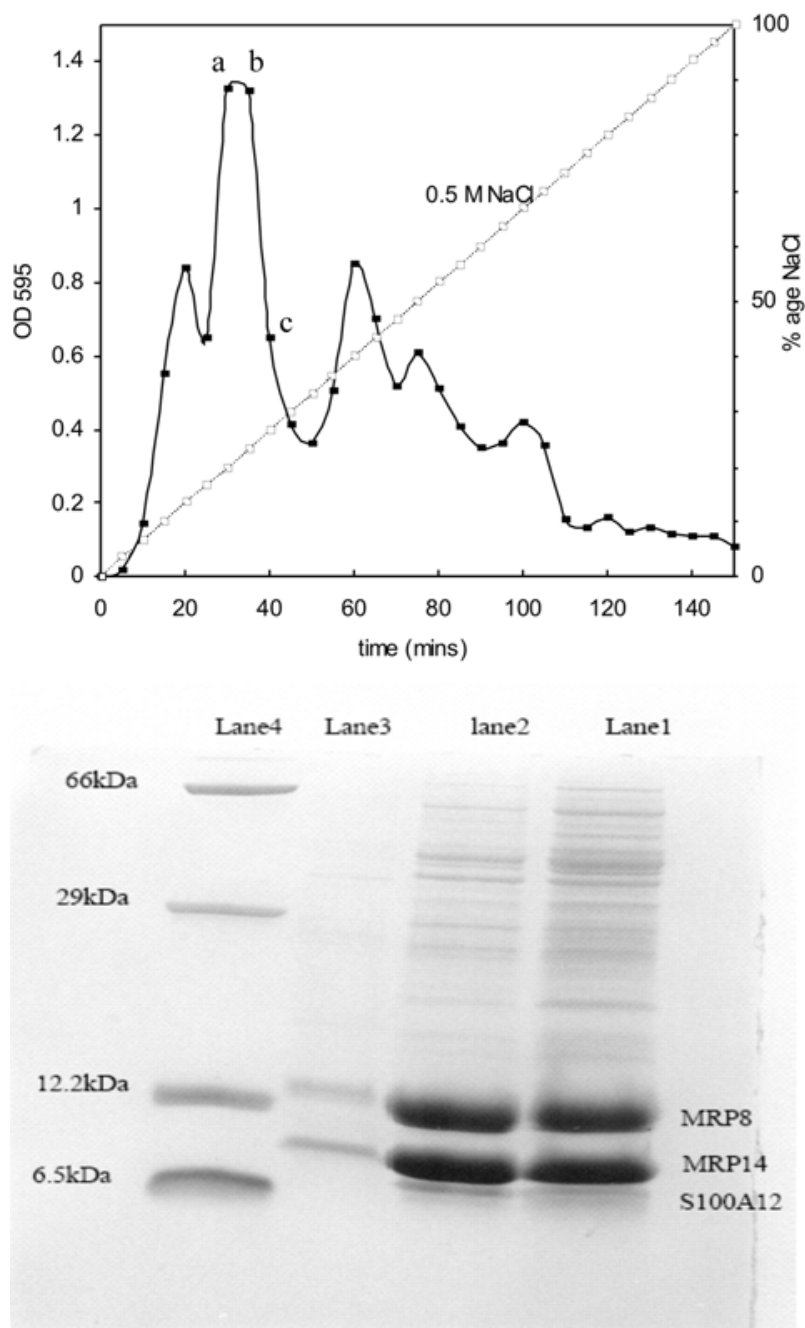

Fig. 1. (a) Neutrophil extract was dialyzed against $25 \mathrm{mM}$ Tris$\mathrm{HCl} \mathrm{pH}$ 8.0, $1 \mathrm{mM}$ EDTA, $1 \mathrm{mM}$ DTT (buffer I), then loaded onto an anion exchange column (Q-Sepharose). Bound proteins were eluted by a linear $\mathrm{NaCl}$ gradient of $0-0.5 \mathrm{M}$ in buffer I. The graph shows the $595-\mathrm{nm}$ trace of eluted proteins by use of Brad ford solution. Majority of MRP8 and MRP14 were eluted from the column at approximately $0.12 \mathrm{M} \mathrm{NaCl}$. Fractions a, b and $\mathrm{c}$ were showed major growth inhibitory against K562. S100A12 also co eluted with calprotectin subunits from anion exchange column. (b) Active pooled fractions against K562 were subjected to tricine SDS-PAGE $(15 \%$ gel $)$ under reducing conditions and protein bands subsequently visualized by Coomasie Blue staining (lanes 1, 2 and 3 are equivalent to fractions $\mathrm{a}, \mathrm{b}$ and $\mathrm{c}$ respectively). Molecular masses are indicated on the left (lane 4).

and $b)$.

Similarly to recent reports (Vogl et al., 1999) and as shown in Fig. 1b, S100A12 also co-eluted with calprotectin subunits from anion exchange column. S100A12 or MRP6 is a recently identified protein that exclusively expressed in neutrophils and it has close homology with both MRP8 and MRP14 (Robinson and Hogg, 2000). 


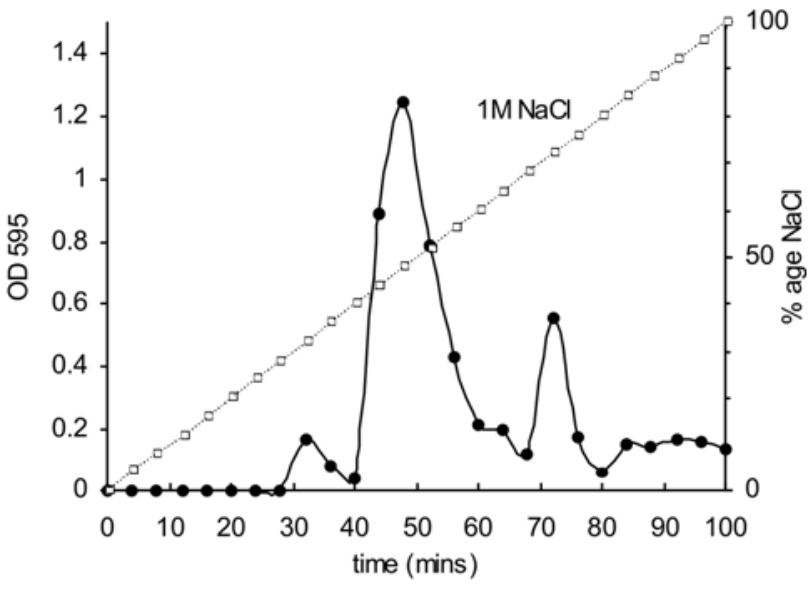

Lane 3 Lane 2 Lane 1

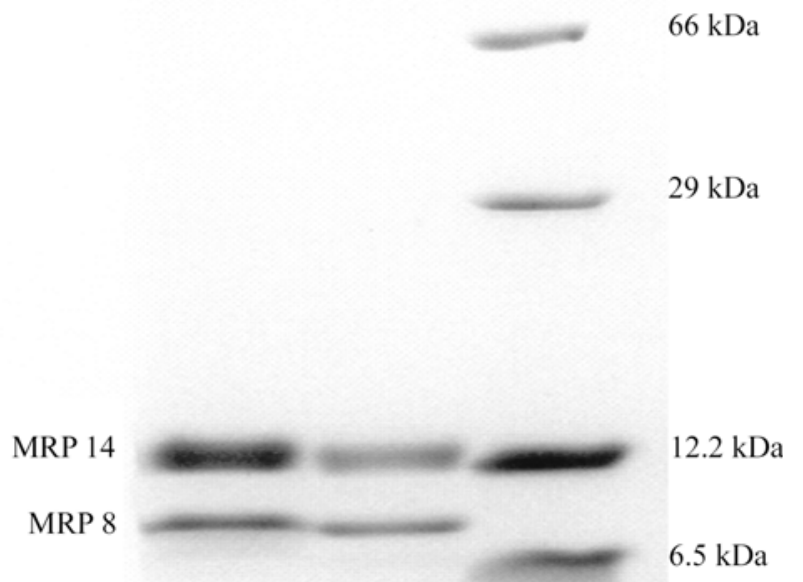

Fig. 2. (a) Calprotectin containing fractions a and b which were obtained from anion-exchange column, were dialyzed against 25 $\mathrm{mM}$ sodium acetate $\mathrm{pH} 4.5,1 \mathrm{mM}$ EDTA, $1 \mathrm{mM}$ DTT, injected onto cation-exchange column (SP-Sepharose). Bound proteins were eluted from the column by the application of $0-1.0 \mathrm{M} \mathrm{NaCl}$ gradient in buffer II. The graph shows the 595-nm trace of eluted proteins by use of brad ford solution. (b) Purified fractions that had been obtained from cation exchange column were subjected to tricine SDS-PAGE $(15 \%$ gel), under reducing conditions (Lane 2 and 3) and protein bands were detected by Coomasie Blue staining. Lane 1 indicates Molecular masses marker.

Fractions $\mathrm{a}$ and $\mathrm{b}$ from anion exchange column that showed major growth inhibitory activity against K562, were further applied to cation exchange column. MRP8 and MRP14 were eluted from the column at approximately $0.5 \mathrm{M} \mathrm{NaCl}$ (Fig. $2 a)$. Figure $2 b$ shows the SDS-page profile of purified sample of calprotectin.

Cell death inducing assay of human calprotectin Various concentrations of purified calprotectin were used to culture of tumor cell line K562 for 24 h, in order to examine its cell

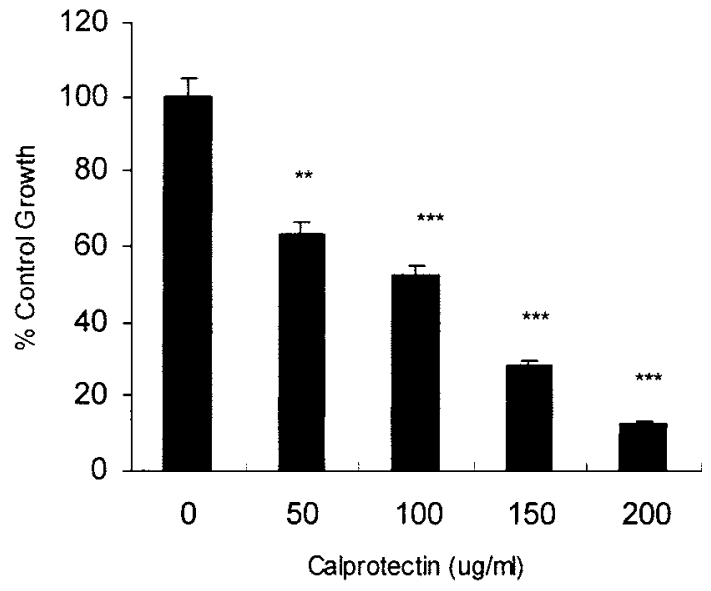

Fig. 3. K562 cells $\left(2 \times 10^{4}\right.$ cells $\left./ \mathrm{ml}\right)$ were cultured with varying concentrations of calprotectin sample for $24 \mathrm{~h}$ and cell proliferation was assessed by MTT assay as described in materials and methods. Results (Cytotoxicity) are presented relative to cell growth under control conditions (absence of calprotectin) and expressed as percentage of control (as 100\%). The vertical bars represent S.D. of triplicate determinations and asterisks indicate ${ }^{*} p<0.05,{ }^{* *} p<0.01$ and ${ }^{* * *} p<0.001$ compared to control (absence of calprotectin).

death-inducing activity. As shown in Fig. 3, growth after $24 \mathrm{~h}$ was significantly reduced by all treatments $(p<0.01, p<0.001)$, $p<0.001$ ), indicating a dose dependent suppression on growing of K562 leukemia cell line.

ANS binding experiments and aggregation study of human calprotectin Previous investigations have revealed that the sequences at both $\mathrm{NH}_{2}$ and $\mathrm{COOH}$ terminals of calprotectin subunits are relatively hydrophobic (Ordink et al., 1987; Hessian et al., 1993). An attractive hypothesis is that these areas of molecule are buried until calcium binding brings about the conformational changes cause their exposure making them potentially available for interaction with other molecules.

ANS, a hydrophobic dye, is useful for monitoring the existence of any exposed hydrophobic surface(s) in molecules (Wagner and MacDonald, 1998). In this study the ANSbinding fluorescence changes of human calprotectin were measured after incubating the protein $(50 \mu \mathrm{g} / \mathrm{ml})$ solution with $70 \mu \mathrm{M}$ of ANS for $15 \mathrm{~min}$, in $0.1 \mathrm{M}$ ammonium acetate, at $\mathrm{pH}$ 7.0. ANS-fluorescence emission spectra were recorded at room temperature between 400 and $600 \mathrm{~nm}$ using an excitation wavelength of $400 \mathrm{~nm}$. As shown in Fig. 4 after incubation of human calprotectin for $30 \mathrm{~min}$ with calcium concentrations in physiological range $(1.0,1.5,2 \mathrm{mM})$ and measurement of ANS-binding fluorescence intensity, indicates a significant increase in emission spectra of calcium-incubated protein relative to the native state. Also, ANS-fluorescence of human calprotectin elevate with calcium in a dose-dependent manner.

ANS-fluorescence enhancement of calcium-incubated protein 


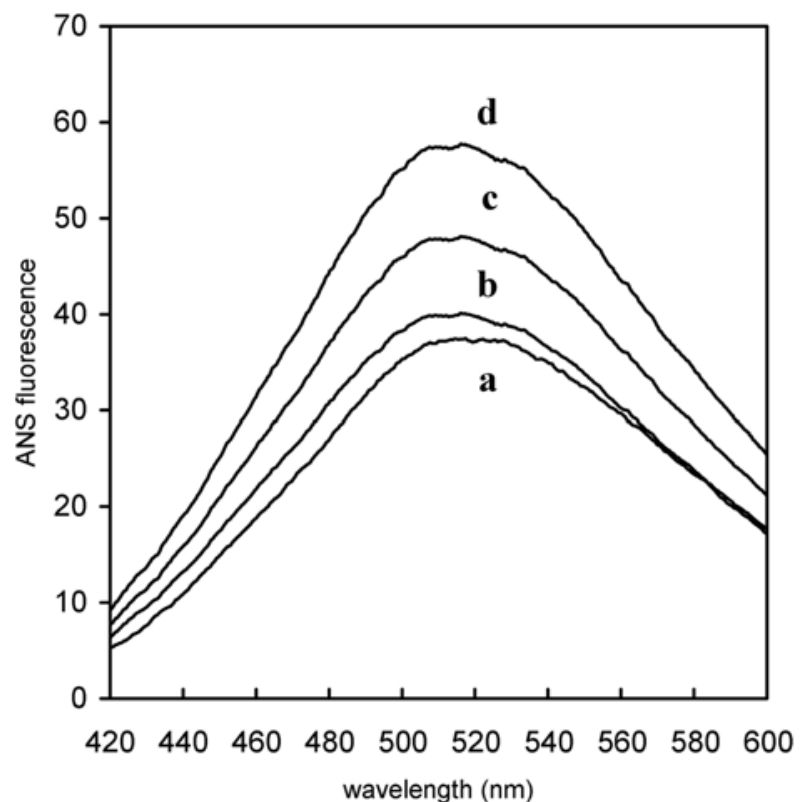

Fig. 4. The ANS fluorescence emission spectra of the human calprotectin $(50 \mu \mathrm{g} / \mathrm{ml})$ in the absence (a) and presence of $1 \mathrm{mM}$ (b), $1.5 \mathrm{mM}(\mathrm{c})$ and $2 \mathrm{mM}(\mathrm{d})$ of calcium in ammonium acetate $(0.1 \mathrm{M})$, at $\mathrm{pH} 7.0$ and $25^{\circ} \mathrm{C}$. The excitation wavelength was $400 \mathrm{~nm}$.

relative to the native state indicates an increase in surface hydrophobicity of human calprotectin that take place during the interaction of protein with calcium. Hydrophobic regions of calprotectin that normally buried within the interior of the protein are probably exposed to aqueous environment upon calcium binding. Calprotectin does not have a signal peptide for membrane anchoring or secretion, but upon calcium binding and protein kinase $\mathrm{C}$ (PKC) activation, protein anchors in and secretes from the membrane respectively (Muesch et al., 1990). Therefore an increase in lipophilicity of human calprotectin in the presence of calcium may be important in the membrane anchoring and membrane penetration of this protein.

Calcium binding induces conformational changes; increase surface hydrophobicity and also make calprotectin prone to aggregation. Aggregation is the interaction of unfolded protein molecules that are responsible for formation of agglomerates of irregular form as a result of incorrect proteinprotein contacts. The aggregation experiments of human calprotectin at the presence of higher concentrations of calcium $(6,8$ and $10 \mathrm{mM})$ were carried out in ammonium acetate, at $\mathrm{pH} 7.0$ and room temperature and the turbidity was monitored by measuring the light absorption at $420 \mathrm{~nm}$ for $180 \mathrm{~min}$. As shown in Fig. 5, calcium at concentration of $6 \mathrm{mM}$ or higher induces the aggregation of human calprotectin. Calcium concentrations lower than $6 \mathrm{mM}$ were also examined at $420 \mathrm{~nm}$ for $180 \mathrm{~min}$, but we did not observed any increased absorbance. Previous investigations demonstrate that calprotectin has more thermal and structural stability at alkaline than acidic pH (Dale et al., 1983). Hence,

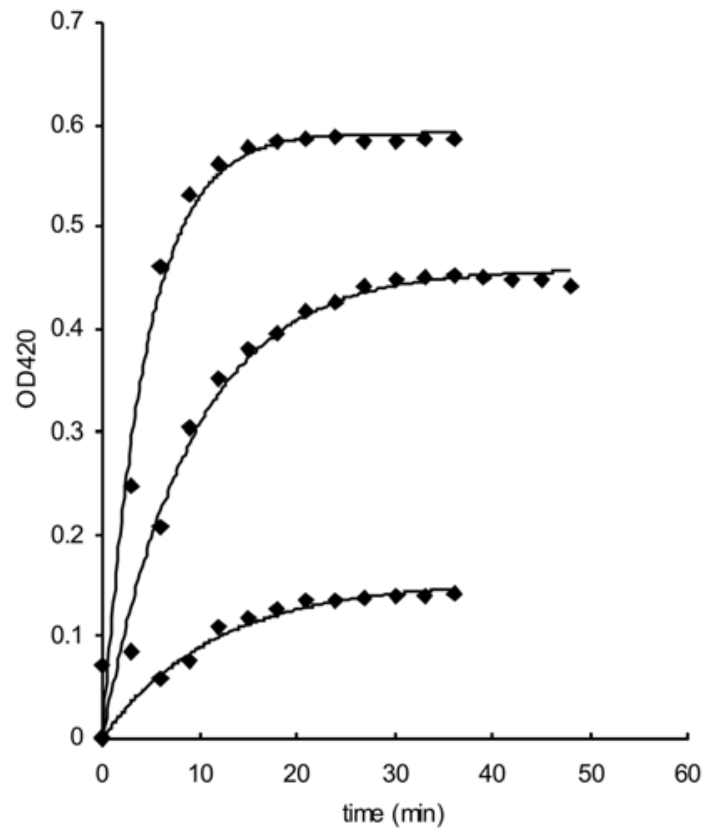

Fig. 5. Aggregation Kinetics of human calprotectin $(50 \mu \mathrm{g} / \mathrm{ml})$, at the presence 6 (a), 8 (b) and $10 \mathrm{mM}$ (c) of Calcium in $0.1 \mathrm{M}$ ammonium acetate at $\mathrm{pH} 7.0$ and $25^{\circ} \mathrm{C}$.

the aggregation experiment of human calprotectin was also carried out at $\mathrm{pH} 8.0$ in the same buffer, indicating that calcium at concentrations 6,8 and $10 \mathrm{mM}$ (as mentioned above) could not induce calprotectin aggregation. This suggests that calprotectin stabilizing conditions such as increase in the $\mathrm{pH}$ has an important role in preventing calcium-induced human calprotectin aggregation.

The calcium binding proteins MRP8, MRP14, and S100A12 have been characterized in myeloid cells; however the relationship among these proteins remains unclear. S100A12 represents a major calcium-binding protein in granulocytes. Calcium binding level of S100A12 is approximately 18 times higher than that of MRP8 and comparable to MRP14 (Vogl et al., 1999). In this study the semi-purified fractions that contain only S100 A12 as contamination were also used as target for the calcium induced aggregation. However, no aggregation was observed, even at the presence of $10 \mathrm{mM}$ calcium. This finding shows that the presence of $\mathrm{S} 100 \mathrm{~A} 12$, a major calcium binding protein, may reduce effective calcium concentration necessary for calprotectin aggregation.

The parameters of equation (1), obtained by fitting the experimental data are listed in Table 1. The staring time and the rate constant for aggregation depend on the calcium concentration. The appearance of a lag period at the initial part of the kinetics curve is probably due to the following reasons. First, aggregation is preceded by a stage of the unfolding of protein molecules, which makes unfolded protein prone to the aggregation. Second, an increment of absorbance becomes appreciable only after the appearance of sufficient 
Table 1. Calprotectin aggregation parameters, calculated based on equation 1

\begin{tabular}{cccc}
\hline$\left[\mathrm{Ca}^{+2}\right] \mathrm{mM}$ & $\mathrm{A}_{\lim }$ & $\mathrm{k}\left(\mathrm{min}^{-1}\right)$ & $\mathrm{t}_{\mathrm{o}}(\min )$ \\
\hline 6 & 0.153 & 0.087 & 81 \\
8 & 0.564 & 0.109 & 36 \\
10 & 0.592 & 0.225 & 15 \\
\hline
\end{tabular}

aggregate in the solution (Kurganov, 2002).

A number of reports indicate that many proteins and peptides are able to aggregate into amyloid assemblies under suitable destabilizing conditions. The common hallmark of some pathological conditions such as Alzheimer, Parkinson, Cystic fibrosis, Type II diabetes and some forms of emphysema is the presence of proteinocious deposits in the affected tissues and organs (Stefani and Dobson, 2003). It seems that calprotectin elevation in the brain, especially in conditions that make protein prone to aggregation may be important in Alzheimer disease, because it has been reported that calprotectin is expressed in brain tissue in this amyloid disease (Akiyama et al., 1994).

It is not clear by which mechanism the calprotectin initiate signaling toward the cell death. It has been reported that early aggregates have an intrinsic ability to impair fundamental cellular processes by interacting with cellular membranes, causing oxidative stress and increases in free calcium that lead to impairment of the cell viability and eventually to cell death (Squire, 2001). It has been shown that antioxidants, such as tocopherol protect cells against aggregates toxicity (Zhang, 2001) and our previous studies also demonstrated that calprotectin cytotoxic effect against the cell lines MOLT4 and K562 has been reversed by $\alpha$-tocopherol (the article has been submitted for publication).

We postulated that cell-death inducing activity of calprotectin may be governed through toxic pre-aggregation species. This is possible because calcium binding may lead to the formation of a toxic variant of calprotectin with sticky (hydrophobic) surface that interact with plasma membrane to kill cells.

Finally in calcium- and fatty acid binding capacity, also in death-inducing activity against tumor cells and bactericide effects, the milk protein $\alpha$-lactalbumin shares similar properties to calprotectin (Stefani, 2004). Also it has been reported that acute phase isoforms of human serum amyloid A (SSAp), similar to calprotectin rises dramatically during inflammatory processes. Both a-lactalbumin and SSAp exhibit cytotoxic effects by forming toxic aggregation species (Stefani, 2004). These similarities led us to suppose that the death-inducing mechanism of calprotectin may be similar to those of SSAp and $\alpha$-lactalbumin.

Acknowledgments This work was financially supported by grants from the Third World Academy of Science (TWAS) and the Research Council of University of Tehran. The authors would like to thanks Dr. F. C. Chilaka for proofreading of the manuscript.

\section{References}

Ackerman, P., Glover, C. V. and Osheroff, N. (1985) Phosphorylation of DNA topoisomerase II by casein kinase II: modulation of eukaryotic topoisomerase II activity in vitro. Proc. Natl. Acad. Sci. USA 82, 3164-3168.

Akiyama, H., Ikeda, K., Katoh, M., McGeer, E. G. and McGeer, P. L. (1994) Expression of MRP14, 27E10, interferon-alpha and leukocyte common antigen by reactive microglia in postmortem human brain tissue. J. Neuroimmunol. 50, 195-201.

Bella, J. and Rossmann, M. G. (1999) Rhinoviruses and their ICAM receptors. J. Struc. Biol. 128, 69-74.

Berntzen, H. B., Olmez, ü., Fagerhol, M. K. and Munthe, E. (1991) The leukocyte protein L1 in plasma and synovial fluid from patients with rheumatoid arthritis and osteoarthritis. Scand. J. Rheumatol. 20, 74-82.

Bogumil, T., Rieckmann, P., Kubuschok, B., Felgenhauer, K. and Bruck, W. (1998) Serum levels of macrophage-derived protein MRP8/14 are elevated in active multiple sclerosis. Neurosci. Lett. 247, 195-197.

Bucciantin, M., Giannoni, E., Chiti, F., Baroni, F., Formigili, L., Zurdo, J., Taddei, N., Ramponi, G., Dobson, C. M. and Stefani, M. (2002) Inherent toxicity of aggregates implies a common mechanism for protein misfolding diseases. Nature 416, 507511.

Burgess, W. H., Jemiolo, D. K. and Kretsinger, R. H. (1980) Interaction of calcium and calmodulin in the presence of sodium dodecyl sulfate. Biochem. Biophysic. Acta 623, 257270.

Crestfield, A. M., Moore, S. and Stein, W. H. (1963) The preparation and enzymatic hydrolysis of reduced and Scarboxymethylated proteins. J. Biol. Chem. 238, 622-627.

Dale, I., Fagerhole, M. K. and Naesgaard, I. (1983) Purification and partial characterization of a highly immunogenic human leukocyte protein L1 antigen. Eur. J. Biochem. 134, 1-6.

Dorin, J. R., Novak, M., Hill, R. E., Brock, D. J. H., Secher, D. S. and van Heynigen, V. (1987) A clue to the basic defect in cystic fibrosis from cloning the CF antigen gene. Nature 326, 614-617.

Edgeworth, J., Freemont, P. and Hogg N. (1989) Ionomycin regulated phosphorylation of the myeloid calcium binding protein P14. Nature 342, 189-192.

Guignard, F., Mauel, J. and Market, M. (1996) Phosphorylation of myeloid related proteins MRP-14 and MRP-8 during human neutrophil activation. Eur. J. Biochem. 241, 265-271.

Heizmann, C. W. and Hunziker, W. (1991) Intracellular calcium binding protein: More sites than insights. Trends Biochem. Sci. 16, 98-103.

Hessian, P. A., Edgeworth, J. and Hogg, N. (1993) MRP8 and MRP14, two abundant $\mathrm{Ca}^{2+}$-binding proteins of neutrophils and monocytes. J. Leuk. Biol. 53, 197-204.

Kerkhoff, C., Klempt, M., Kaever, V. and Sorg, C. (1999) The two calcium-binding proteins, S100A8 and S100A9 are involved in the metabolism of arachidonic acid in human neutrophils. J. Biol. Chem. 274, 32672-32679.

Klempt, M., Melkonyan, H., Nacken, W., Wiemann, D., Holtkemper, U. and Sorg, C. (1997) The heterodimer of the $\mathrm{Ca}^{2+}$-binding proteins MRP-8 and MRP-14 binds arachidonic acid. FEBS Letters 408, 81-84.

Lawrance, I. C., Fiocchi, C. and Chackravarti, S. (2001) 
Ulcerative colitis and Crohns disease: distinctive gene expression profiles and novel susceptibility candidate genes. Hum. Mol. Genet. 10, 445-456.

Morishima, Y., Gotoh, Y., Zieg, J., Barrett, T., Takano, H., Flavell, R., Davis, R. J., Shirasaki, Y. and Greenberg, M. E. (2001) $\beta$ amyloid induces neuronal apoptosis via mechanism that involve the c-jun N-terminal kinase pathway and the induction of fas ligand. J. Neurosci. 21, 7551-7560.

Mossman, T. (1983) Rapid colorimetric assay for cellular growth and survival: Application to proliferation and cytotoxicity assays. J. Immunol. Methods. 65, 55-63.

Muesch, A., Hartmann, K., Rohde, A., Rubartellio, R. and Rapopart, T. A. (1990) A novel pathway for secretory proteins. Trends Biochem. Sci. 15, 82-86.

Müller, F., Frøland, S. S., Aukrust, P. and Fagerhol, M. K. (1994) Elevated serum calprotectin levels in HIV-infected patients: The calprotectin response during ZDV treatment is associated with clinical events. J. Acquir. Immune Defic. Syndr. 7, 931-939.

Murao, S., Collart, F. R. and Huberman, E. (1998) A protein containing the cystic fibrosis antigen is an inhibitor of protein kinases. J. Biol. Chem. 262, 8356-8360.

Murao, S., Collart, F. R. and Huberman, E. (1989) A protein containing the cystic the fibrosis antigen is an inhibitor of protein kinase. J. Biol. Chem. 264, 8356-8360.

Ordink, K., Cerletti, N., Bruggen, J., Clerc, R. J., Tarcsay, L., Zwadlo, G., Gerhards, G., Shlegel, R. and Sorg, C. (1987) Two calcium-binding proteins in infiltrate macrophages of rheumatoid arthritis. Nature 330, 80-82.

Rammes, S., Kewitz, G., Versmold, H., Niggemann, B. and Rammes, A. (1997) Myeloid related protein (MRP)8 and MRP14, calcium binding proteins of the S100 family, are secreted by activated monocytes via a novel tubulin-dependent pathway. Pediatr. Allergy Immunol. 8, 153-155.

Robinson, M. J. and Hogg, N. (2000) A comparison of human S100A12 with MRP-14 (S100A9). Biol. Biophys. Res. Comm. 275, 865-870.

Roth, J., Burwinkel, F., VandenBos, C., Goebeler, M., Vollmer, E. and Sorg, C. (1993) MRP8 and MRP14, S-100-like proteins associated with myeloid differentiation, are translocated to plasma membrane and intermediate filaments in a calciumdependent manner. Blood 82, 1875-1883.

Satoru, Y., Mikami, M., Kazusa, T. and Yamazaki, M. (1997) Growth inhibitory and apoptosis-inducing activities of calprotectin derived from inflammatory exudates cells or normal fibroblasts: regulation by metal ions. J. Leukocyte Biol.
61, 50-57.

Schagger, H. and von Jagow, G. (1987) Tricine-sodium dodecyl sulfate-polyacrylamide gel electrophoresis for the separation of proteins in the range from 1 to $100 \mathrm{kDa}$. Anal. Biochem. 166, 368-379.

Skoog, W. and Beck, W. S. (1956) Studies on the fibrinogen, dextran and phytohemagglutinin methods of isolating leukocytes. Blood 11, 436-454.

Squier, T. C. (2001) Oxidatve stress and protein aggregation during biological aging. Exp. Gerontol. 36, 1539-1550.

Stefani, M. and Dobson, C. M. (2003) Protein aggregatron and protein toxicity: new insights into protein folding, misfolding diseases and biological evolution. J. Mol. Med. 81, 678-699.

Stefani, M. (2004) Protein misfolding and aggregation: new examples in medicine and biology of the dark side of the protein world. Biochem. Biophys. Acta 1739, 5-25.

Steinbakk, M., Naess-Andersen, C. F., Lingaas, E., Dale, I., Brandtzaeg, P. and Fagerhol, M. K. (1990) Antimicrobial actions of calcium binding leukocyte $\mathrm{L}_{1}$ protein, calprotectin. Lancet. 336, 763-765.

Stetler, D. A. and Rose, K. M. (1982) Phosphorylation of deoxyribonucleic acid dependent RNA polymerase II by nuclear protein kinase NII: mechanism of enhanced ribonucleic acid synthesis. Biochemistry 21, 3721-3728.

Teigelkamp, S., Bhardwaj, R. S., Roth, J., Meinardus-Hager, G., Karas, M. and Sorg, C. (1991) Calcium independent complex assembly of the myeloid differentiation proteins MRP-8 and MRP-14. J. Biol. Chem. 266, 13462-13467.

Tibble, J., Sigthorsson, G., Foster, R., Sherwood, R., Fagerhol, M. and Bjarnason, I. (2001) Faecal calprotectin and faecal occult blood tests in the diagnosis of colorectal carcinoma and adenoma. Gut. Sep 49, 402-408.

Vogl, T., Propper, C., Hartmann, M., Strey, A., Strupat, K., Van den Bos, C., Sorg, C. and Roth, J. (1999) S100A12 is expressed exclusively by granulocytes and acts independently from MRP8 and MRP14. J. Biol. Chem. 274, 25291-25296.

Wagner, D. W. and MacDonald, P. J., (1998) The fluorescence enhancement of 1-anilinonaphtalene-8-sulfonate (ANS) by modified $\beta$-cyclodextrins. J. Photochem. Photobiol. Chem. 114, 151-157.

Zhang, L., Xing, G. Q., Barker, J. L., Chang, Y., Maric, D., Ma, W., Li, B-S. and Rubinow, D. R. (2001) $\alpha$-lipoic acid protects rat cortical neurons against cell death induced by amyloid and hydrogen peroxide through the Akt signaling pathway. Neurosci. Lett. 312, 125-128. 